amelioration. I do not see that any real harm has been proved to have occurred, except in the instance of the wife of one of the plaintiffs, Mr. Fripp, who looked into one of these sick carriages and is said to have so caught the disease ; but if it is true that these carriages have been allowed to stop at public-houses for drink or cliat, it is clear that danger might be caused; and even in Mrs. Fripp's case, though it may be true that she owed her calamity to her own imprudence, it is clear that the occurrence ought to have been rendered impossible. It should be known, however, that these carriages are not the property nor under the control of the Board. They belong to the individual vestries. I think a far more effectual precaution than the "disinfection" spoken of by the jury would be to place the carriages, as well as the reception and treatment of the patients, under the control of the Asylums Board, who would be responsible for their proper regulation. And let it not be forgotten that even if we were obliged to conclude that there is distinct evidence of unavoidable danger in moving small-pox and fever patients to hospital (the contrary of which, I contend, is the conclusion to which all experience points), yet we must compare this with the danger of leaving them at home. I have heard it stated that Dr. S. Gibbon told the jury that he believed the two recent epidemics of small-pox were so severe in consequence of the patients being carried through the streets. May I inquire if this is true? and, if so, on what grounds Dr. Gibbon made the statement? One would have thought $\dot{c}$ priori that any slight risk involved in the carriage of the patient would have been as nothing compared to the rast benefit derived from his subsequent isolation.

As to any disregard of the rights of the inhabitants of Hampstead, I must say that I am totally unable to discover any thing to support such a charge. The hospital was placed there because there only did we think we could find a suitable site. The Managers then believed, and still believe, that no danger whatever would accrue from it.

I find a general impression prevails that this hospital in some way obstructs the way to Hampstead Heath. Those who have been to the place know how absurd this is ; still I think it as well to say that no one going to the Heath from any part, or by any road, need see or know of the existence of the hospital, nor is he in any greater danger of catching small-pox from passing along the road, out of which the lane opens in which the hospital is placed, than he would be of atching fever by driving along the Liverpool-road, or of catching small-pox by a visit to Highgate. This argument also has been used to create an impression on the public, but cannot have been seriously believed in by anyone who is acquainted with the circumstances.

I have, I fear, been prolix, but the subject is so complicated, and, I find, so generally misunderstood, that I have been unable to avoid writing at some length. Let me conclude with an earnest appeal to the medical men who thought it their duty to give evidence on behalf of the plaintiffs, and especially to the respected President of the College of Physicians, to explain their evidence, or, at any rate, to see that it is published in extenso. The latter especially, from his public position, is bound not to oppose the action of a public body taken, as everyone admits, with the single object of carrying out the beneficent intentions of the Legislature, except for the gravest reasons. If public danger had been caused by the action of the Asylums Board-if real proof had been within his knowledge of the spread of smallpox or fever in consequence of their mismanagement-if he had reason to know that the interior arrangements or treatment of the sick had been bad, then I can imagine that the President of the College would feel it his duty to interfere. But if he was brought there, as the slight sketch of his evidence in The Times seems to show, merely to add anthority to the names of the medical witnesses for the plaintiffs, and to tell the jury what everyone knew before-viz., that no one likes to live near a small-pox hospital-it may be questioned whether he should have lent himself to such a manouvre. In any case the managers have a right to ask so great an authority, as he has mixed himself up in the matter, for counsel as well as criticism.

December 10th, 1878 I am, Sir, yours \&c., Holmes's letter, but as a statement of the views of the Board it is worthy of consideration. The points of difference between Mr. Holmes and ourselves appear to be minor matters of judgment, and to rediscuss them in detail would occupy too much of our space. The general opinion which we expressed we adhere to, for, whoever may be responsible for the closure of the Fleet-road access, it is only one and not all the plaintiffs, and the mere fact that it was so far a private road that it could be closed, and that the Board did not ascertain this fact, shows that they did not act with proper caution. Nor, on the other points of difference, do we think that the view adopted by Mr. Holmes would be generally accepted by uninterested persons. The discrimination of convalescent wards can hardly be made from their external appearance, nor do we suppose that there can be any rule which will always be enforced that the ward nearest the boundary wall will be used for none but convalescents. We have yet to learn that small-pox is not lighly contagious from convalescents.-ED. $\mathrm{K}$.

\section{THE ACTION OF HYOSCYAMINE AND ITS RELIABILITY.}

\section{To the Editor of THE LANCET.}

SIR,-The question of the reliability of a drug is a most important one, and the varying effects of different samples may give to different observers very erroneous ideas of its action, and consequent dose.

I have hitherto found Merck's extractive amorphous alkaloid, obtained through Messrs. Harvey and Reynolds, of Leeds, a very reliable and uniform preparation, and entirely corroborate Dr. Lawson's observations, which appeared in THE LANCET recently. I have had many samples, each obtained in the same way, and have noticed no variation in the effects produced on the same patients, some of whom have been taking the drug at intervals for many months. Very lately, however, I have received two samples which certainly have proved almost, if not quite, inert. The hyoscyamine I had hitherto received was of a dark brownish colour, with a slight dirty-greenish tinge, and of a peculiar disagreeable smell, almost mousey; but a sample which I received a few weeks ago was of a much lighter colour, almost a golden brown, with a smell more like that of gas liquor than anything else. I noticed the difference in colour, and the attendants drew my attention to the fact that the medicine did not produce the same effect as that which the patients had previously taken. I increased the dose, but could not find that it produced any of the physiological effects of the previous samples. I wrote to Messrs. Harvey and Reynolds; they admitted that there had been a difference in the colour of the preparation, and regretted that it should vary, and they kindly sent me a fresh sample. I noticed that this was of the same light colour, and, having doubts as to its efficacy, I determined, if possible, to test it carefully, and compare its action with that of the former samples. I obtained from a friend, Dr. Swanson, of York, a small portion of a sample of the alkaloid procured from Messrs. Harvey and Reynolds some months back, and which was of the same colour that my previous samples had been. I then made up a solution of each in the same way, and to give a clear idea of what the difference in colour was, I found that in a solution-one grain to twenty-four minims-the colour of the new sample was as nearly as possible that of tincture of myrrh, and the colour of the older that of tincture of digitalis. I selected two patients who had previously taken hyoscyamine, and were particularly susceptible to its action-a patient, A. B., suffering from epileptic mania, and a patient, C. D., a case of pure mania. On successive days I gave each a dose of hyoscyamine, and at the same time. On the first day, they each had a dose of one-eighth of a grain of the last sample of the alkaloid, and I saw and watched them closely during the ensuing four hours. The pupils of the patient A. B. measured $1+1$ lines at the time of administration of the drug, and during the four hours no variation beyond an immeasurable one took place; there was no observable change in her in any way, her condition remained loud and boisterous. The pupils of the patient C. D. measured $1 \frac{1}{4}$ lines at the time of administration, and four hours afterwards the greatest measurement had been $1 \frac{1}{2}$ lines. There 
was no change in this patient. The following day at the same time, the patient A. B. had one-eighth of a grain of the old sample given in the same way exactly as the former. At the time of administration the pupil measured $1 \frac{1}{3}$ lines. One hour after administration the patient, who had been very sleepy, had staggered about, and finally fell; she was quite unable to stand, spoke slowly and exactly as if drunk; her words were almost undistinguishable; her pupils measured 21 lines. She slept the most part of the next few hours, but four hours after the administration of the drug her pupils measured $3 \frac{2}{3}$ lines, and her excited condition did not recur during the whole of that day. The patient $C$. $D$. had one-sixteenth of a grain ; at the time of administration the pupils measured 1 line; during the next four hours she was quite quiet, her constant talking ceased. At the end of four hours her pupils measured 21 lines. I am informed that one grain of the newer sample was given to a rabbit with no result, and that one-third of a grain of the older sample produced all the nsual symptoms.

The results of the above experiments prove conclusively that some samples of the alkaloid are almost inert, but when the amorphous extract has the dark tint, I have never known it fail to produce, in doses of one-eighth of a grain, and even one-sixteenth, decided proofs of its action.

I make and keep a concentrated solution which does not change to the extent the dilute solutions do. I have usually kept a solution, one grain in twenty-four minims, made up of alcohol eight minims, spirits of sulphuric ether four minims, water twelve minims. This solution may be mixed with water for administration by the mouth, or it may be used hypodermically with perfect safety. I have used it in this way now for some time. Dr. Lawson has adopted, I believe, the same formula, but amended it by making it one grain in forty minims, for the greater convenience of administration.

More lately I have received, through the courtesy of Messrs. Harvey and Reynolds, another example of hyoscyamine, and I have tested this carefully in a similar manner to the last. This sample was not inert, but its effects were certainly not altogether the same as those produced by the earlier sample, some of them being at variance with the known action of the drug; neither was it so powerful as regards the effects common to both.

These variations in the different samples (from absolute inertness to effects denoting powerful activity) are quite sufficient to account for the discrepancies between the letters which appeared in THE LANCET a few weeks back, from observers describing the effects of the doses they had given; and when it is remembered that these samples were obtained from the same wholesale chemist and from the same manufacturer, how much more likely are the effects to vary when obtained from different manufacturers.

It appears to me-after carefully watching the effects of these different samples obtained from so eminent a chemist as La Merck, and presumably prepared by the same processthat this amorphous preparation is a compound of more than one alkaloid, and that their varying proportions produce the varied effeets to be observed of the different samples upon the same patients, whilst absolute inertness must denote either an absence of alkaloids, or that they are negatived by some fault in the method of preparation. That these results should occasionally occur is much to be deplored, as they lead to a distrust and want of confidence in the drug which may prevent it from being used when its administration may be extremely beneficial, and may retard its more general investigation; and this is all the more to be regretted, inasmuch as hyoscyamine is undoubtedly a most valuable drug in the treatment of insanity, indeed one of the most valuable we have. It produces a most beneficial effect in most of the forms of mania, and it certainly will produce a continued abatement of mental excitement when all other drugs fail.

In conclusion, I must say that Messrs. Harvey and Reynolds have offered every facility for an examination of their different samples of this drug, and have expressed their great regret that they should have varied.

Since writing the above, I have received from M. Merck, through Messrs. Harvey and Reynolds, a letter to the effect that, owing to the supply of the leaves of hyoscyamus falling short, he had been manufacturing the extractive alkaloid from the root, and that this accounted for the variation in colour, but he maintained that it did not interfere with the activity of the drug. From this $I$ am the more inclined to believe, what I had suspected, that this extractive, especially when prepared from the root, contains more than one active principle; and it will be of great advantage when we are able to obtain the pure alkaloid in sufficient quantity and at a moderate price.

I am, Sir, your obedient servant,

Engledue Prideaux,

Norember, 1878. Assistant Medical Officer, Friends' Retreat, York.

\section{BIRMINGHAM.}

(From our own Correspondent.)

THE recently-issued quarterly report of Dr. Alfred Hill, the medical officer of health, shows that the death-rate has been unusually high, $25 \cdot 90$, while for the corresponding quarter last year it was $22 \cdot 25$, and in $1876,22 \cdot 47$. The excessive rate is due to the large number of death from diarrhœe and scarlatina, 534 fatal cases of the former and 304 of the latter having occurred; 69 per cent. of the diarrhoa cases were in infants under one year of age. Variola caused two deaths. The total zymotic death-rate was 10.4 per 1000 , which is considerably above the average of the last three years. It is gratifying to find that the Borough Hospital is being utilised to a greater extent than formerly, 139 cases of scarlatina and 6 of variola having been taken there during the quarter.

The Hospital Sunday collections have, in spite of the great commercial depression, been unprecedentedly good, and the Queen's Hospital will receive the handsome sum of $\$ 6400$.

The governors of that charity held a meeting on the 27th ult., under the presidency of the Mayor, to consider the position of the hospital and its future prospects. Mr. J. Chamberlain, M.P., said that the prosperity of such an institution as the Queen's Hospital was one of universal concern. The present management of the institution deserved the confidence of the inhabitants of the town and neighbourhood, and the good work previously done could be continued if the means of doing so were forthcoming. No doubt the free system was the right system, and the embarrassment of the hospital was not due to that cause, but to the great exten. sions which were made a few years ago. It should be remembered that these extensions were necessary, and that, owing to the increase of population, the hospital was not too large for the needs of the town. He concluded by moving a resolution as to the necessity of at once making an effort to obtain $£ 4500$ to free the committee from debt, and to secure an increase in the subscriptions of at least $£ 1000$. He generously headed the list of contributions with a sum of one hundred guineas; a like sum was contributed by Dr. Heslop, and other sums of smaller amount have since been announced, which will in all probability in the course of a short time make up the required sum, and relieve the hos. pital from the incubus of debt, under which it has so long laboured.

The Birmingham Philosophical Society, of which Dr. Heslop is the President for the present session, has just issued its annual report, from which it appears that the number of members has risen from 87 to 105 . At the last meeting a valuable and interesting communication was made by Dr. Norris, the Professor of Physiology in Queen's College, "On the mode of Development of Mammalian Blood." The paper was illustrated by means of microphotographs and the oxyhydrogen light, and was received with great attention by a large number of members of the medical profession, who had courteously been invited by the President and Council.

Birmingham, Dec. 9th, 1878.

\section{ROYAL COLLEGE OF SURGEONS.}

AT an ordinary meeting of the Council, held on Thursday last, a report of the president and vice-presidents, recommending the application of the Erasmus Wilson Fund to the promotion of the study of Pathology (including Dermatology), among the fellows and members of the College, by original research and by lectures, was read and adopted.

The members of the last Board of Examiners in Anatomy 